\title{
PROPOSED IMPLEMENTATION OF PROTECTION SYSTEMS AGAINST DIESEL ENGINE FAILURE (DIESEL ENGINE RUNAWAY)
}

\author{
Jean da Silva de Abreu Silva ${ }^{1}$, Brenda Lira dos Santos ${ }^{2}$, Anderson de Oliveira Castro ${ }^{3}$, \\ Jarielson García cruz ${ }^{4}$, Wandesson Santos $\mathrm{Cruz}^{5}$, Danilo Reis da Silva ${ }^{6}$
}

1,2,3,4,5 Centro Universitario do Norte - UNINORTE - Laureate Universites, Brasil, Rua Leonardo Malcher, 715. Centro, Manaus/AM.

Email: jean.s.abreu@hotmail.com, brendalira71@live.com, Anderson.castro@uninorte.com.br, jarielsongarcia@hotmail.com, wandersson93@gmail.com, dimooreis@gmail.com

Received: May 15th, 2019

Accepted: May 23th 2019

Published: September $30^{\text {th }}$, 2019

Copyright (02016 by authors and Institute of Technology Galileo of Amazon (ITEGAM). This work is licensed under the Creative Commons Attribution International License (CC BY 4.0). https://creativecommons.org/lice nses/by/4.0/

\begin{abstract}
When we mention power generation and locomotion, it is observed that the application of internal combustion engines is essential. In view of the large scale of application of these engines, in particular the compression-ignition engines, known as Diesel cycle engines, various problems inherent to the operation and maintenance of them are presented. One of the critical problems of the Diesel engine is a defect known as engine runaway. This problem occurs for several factors, but the lack of proper maintenance is the main reason. When the defect occurs there is no safe method of shutting down the diesel engine, generating loss of the motor and risk the human integrity is imminent. In this way, this article proposes a system of protection against engine firing using a system of locking valves. This system cuts the airflow at admission, causing the failure of the air to not allow combustion. The project was entirely developed in AutoCAD and presented only for theoretical reference requiring the implementation in the laboratory for conducting controlled trials.
\end{abstract}

Keywords: Diesel, system, Engines.

\section{RESUMO}

Quando mencionamos geração de energia e locomoção, observa-se que a aplicação dos motores de combustão interna é essencial. Tendo em vista a larga escala de aplicação destes motores, em especial os motores de ignição por compressão, conhecidos como motores do ciclo Diesel, vários problemas inerentes a operação e manutenção dos mesmos são apresentados. Um dos problemas críticos do motor à Diesel é um defeito conhecido como disparo do motor. Este problema ocorre por vários fatores, porém a falta de manutenção adequada é principal motivo . Quando o defeito ocorre não existe método seguro de desligar o motor a diesel, gerando prejuízo da perda do motor e risco a integridade humana é eminente. desta forma, o presente artigo propôs um sistema de proteção contra disparo do motor utilizando um sistema de válvulas de bloqueio. Este sistema corta o fluxo de ar na admissão fazendo com que a falta do mesmo não possibilite a combustão. O projeto foi inteiramente desenvolvido em AutoCAD e apresentado apenas para referencial teórico necessitando da implementação em laboratório para realização de ensaios controlados.

Keywords: Diesel, Sistema, Motores. 


\section{INTRODUÇAO}

Tendo em vista a larga escala de utilização dos motores de combustão interna (MCI), em especial os motores de ignição por compressão (MIE) ou motores ciclo Diesel. são amplamente utilizados em veículos para a locomoção de cargas e pessoas, introduzido em veículos leves como carros, caminhonetes e motos, e também em veículos pesados como caminhões, ônibus, locomotivas, navios e motor estacionário, devido o potencial de falha crítica do motor diesel, o disparo de um motor diesel não é tão raro que ocorram, quando esse fenômeno ocorre, na maioria das vezes, as consequências são desastrosas e a perda total do motor a diesel, um motor disparado é extremamente imprevisível, não há meio seguro de interromper o processo, haja vista que não existe dispositivo de proteção contra disparo do motor.

Sendo assim, o presente trabalho visa desenvolver um dispositivo para evitar danos mais graves no motor - diesel. Desenvolvemos um sistema de proteção contra potencial falha dos motores à diesel, haja vista que falta da manutenção acelera o desgaste natural do componente do motor, inerente a utilização da rotina de trabalho, a manutenção é essencial, Assim, a origem do sistema de proteção do contra potencial de falha do motor diesel visa uma solução prática, impedindo danos mais gravem que ocorram, utilizando conhecimentos adquiridos durante o curso acadêmico de Engenharia Mecânica centro universitário do norte.

Esse processo de reformulação o comércio automotivo no seguimento de manutenção e reparos em veículos de linha pesada, tem passado por uma evolução significativa nas últimas décadas, com as mudanças que se desenvolvem através de um maior índice de automação e do uso de equipamentos tecnológicos, buscando sempre inovações em desempenho, custo e qualidade, que tem se tornado armas estratégicas de competitividades e concorrência para que sejam capazes de obter o sucesso nessa categoria. Por outro lado, a manutenção desses veículos deve acompanhar essas melhorias, empregando todas as técnicas e equipamentos disponíveis para um mantimento mecânico moderno [1].

\section{REFERENCIAL TEÓRICO}

\section{II.1 NOÇÕES BÁSICAS DE MOTORES DIESEL}

Motores de combustão interna são dispositivos que transformam calor em trabalho, mas especificamente a energia química que é a queima do combustível em energia mecânica. Essa transformação ocorre através de uma sequência de processos na parte interna do motor [2].

Os motores de combustão interna (MCI), que possuem uma larga escala de utilização, são mais utilizados em veículos para a locomoção de cargas e pessoas. Neste campo de trabalho ele é introduzido em veículos leves como carros, caminhonetes e motos, é também em veículos pesados como caminhões, ônibus, locomotivas, navios [3]

Conforme [2], os motores de combustão podem ser classificados em decorrência da forma de se obter o trabalho, são eles:

- Motores alternativos: este é o tipo de motor mais comum, o trabalho é obtido pelo movimento de um pistão, transformando em rotação constante por um sistema de biela-manivela.

- Motores de impulso: o trabalho é obtido pela força de reação dos gases expelidos em alta velocidade pelo motor. Ex: motor a jato e foguetes.

Quando à ignição dos motores alternativos são divididos de dois tipos, os motores de ignição por faísca ou motores ciclo Otto e os motores de ignição por compressão ou motores ciclo
Diesel. O que difere esses dois tipos de motores é justamente a forma com que se ocorre à queima da mistura [2].

Nos motores do ciclo Otto o pistão comprime a mistura ar-combustível é posteriormente libera a faísca para promover a combustão [2], já o motor ciclo diesel apenas comprime o ar e posteriormente pulveriza o combustível na massa de ar comprimida que se encontra aquecida devida a compressão, e dessa forma ocorre à combustão sem a necessidade de uma faísca [4]. Para que ocorra a reação de forma espontânea nos motes diesel, a temperatura do ar deve ser suficiente elevada, essa temperatura é chamada de temperatura de autoignição, para uso do combustível diesel essa temperatura é aproximadamente $250^{\circ} \mathrm{C}$ [2].

Os motores Diesel possuem uma taxa de compressão superior aos motores do ciclo Otto, enquanto os motores do ciclo Otto possuem uma taxa de 10:1 até 14:1 utilizando etanol e 8,5:1 até 13:1 utilizando gasolina, os motores Diesel trabalham como uma compressão de 15:1 até 24:1, essa compressão é necessária para que se ultrapasse a temperatura de autoignição do combustível [2].

Referente ao número de tempos do ciclo de operação, os motores Diesel são classificados como motores de quatro tempos, neste caso o pistão faz cursos, o que representa duas voltas da manivela do motor, desta forma, se completa um ciclo. Esses processos ocorrem ciclicamente, que resulta na transformação da energia química para a mecânica. Cada ciclo/tempo possui sua nomenclatura, são admissão, compressão, expansão e escape [2]. A Figura 1 representa o ciclo de um motor de quatro tempos.

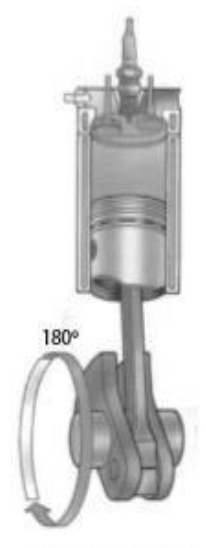

$1^{\circ}$ Tempo Admissáo

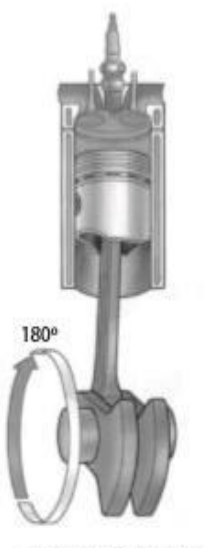

$2^{\circ}$ Tempo Compressáo

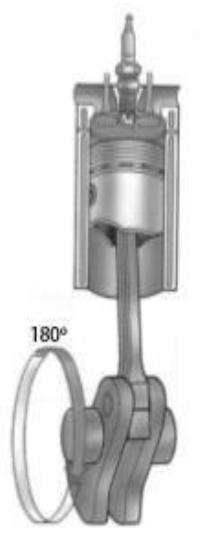

$3^{\circ}$ Tempo Expansáo

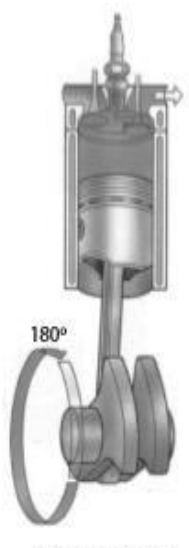

$4^{\circ}$ Tempo Escape
Figura 1. representa o ciclo de um motor de quatro tempos.

Fonte: [2].

\section{Tempo de Admissão:}

O pistão desloca-se do ponto morto superior (PMS) ao ponto morto inferior (PMI). Neste movimento o pistão dá origem a uma sucção (depressão) que causa um fluxo de gases através da válvula de admissão (V.A), que se encontra aberta. O cilindro é preenchido com mistura combustível-ar ou somente ar nos motores de injeção direta de combustível (GDI) se for de ignição por faísca, ou por ar (apenas ar), nos Motor de ignição espontânea (MIE) [2].

\section{Tempo de Compressão:}

Fecha-se a válvula de admissão e o pistão se desloca do PMI ao PMS, comprimindo a mistura ou apenas ar, dependendo respectivamente se o motor é um Motor de ignição por Faísca MIF ou Motor de ignição espontânea - MIE. Neste segundo caso a compressão deverá ser suficientemente elevada para que seja ultrapassada a TAI do combustível [2]. 


\section{Tempo de Expansão:}

No MIF, nas proximidades do PMS, salta a faísca que provoca a ignição da mistura, enquanto no MIE é injetado o combustível no ar quente, iniciando-se uma combustão espontânea. A combustão provoca um grande aumento da pressão, o que permite "empurrar" o pistão para o PMI, de tal forma que o Fluido Ativo - FA sofre um processo de expansão. Esse é o processo que realiza o trabalho positivo (útil) do motor.

\section{Tempo de Escape:}

Com a válvula de escape aberta, o pistão desloca-se do PMI ao PMS, "empurrando" os gases queimados para fora do cilindro, para reiniciar o ciclo pelo tempo de admissão [2].

\section{II.2 TURBOCOMPRESSOR}

O turbocompressor é normalmente também denominado de turbina, turbocharger, turbo alimentador ou turbo (Figura 2). Constituído por um conjunto de dois rotores montados nas extremidades de um eixo, a turbina é acionada pela energia cinética dos gases da descarga. $\mathrm{O}$ ar quente impulsiona o rotor quente fazendo que o rotor frio, na outra extremidade, impulsione o ar para os cilindros. Nos motores do ciclo diesel o turbocompressor tem como objetivo aumentar a pressão do ar no coletor de admissão acima da pressão atmosférica. Isso aumenta a massa de ar sem aumento do volume. O resultando é mais combustível injetado e mais potência. O turbocompressor aumenta a potência em torno de $35 \%$ e reduz o consumo específico de combustível em torno de $5 \%$ [5].

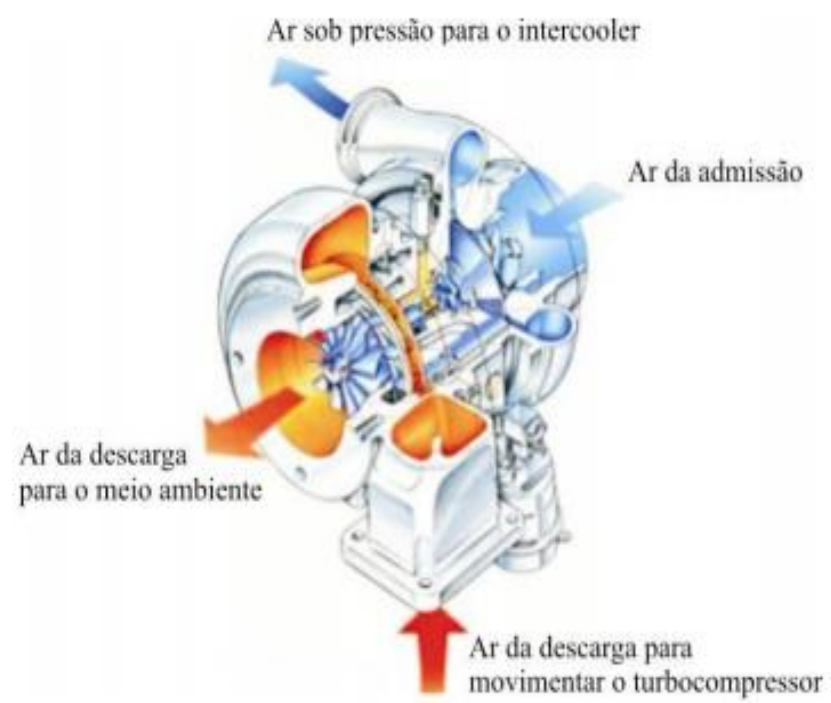

Figura 2. turbocompressor, turbo alimentador, turbina ou turbo. Fonte: [5].

\section{II.3 OBJETIVOS}

A motivação para a realização deste trabalho se dá pela larga utilização de veículos e máquinas pesadas, Motor de ignição espontânea - MIE, devido potencial de falha crítica do motor diesel, o disparo de um motor diesel não é tão raro que ocorram, quando esse fenômeno ocorre, as consequências são desastrosas e medo provocado as pessoas envolvidas são perfeitamente justificado, a criação de um dispositivo contra potencial de falha crítica dos motores a diesel. Assim evitando danos mais grave ao motor.

\section{Disparo de Motor à Diesel:}

É o seu funcionamento, totalmente descontrolado, em rotações altíssimas, além das máximas de projeto. Mesmo se cortando a alimentação de combustível não é possível desligar o motor, tampouco, reduzir a sua velocidade. Nessas condições, é comum o lançamento de uma grande quantidade de fumaça pelo escapamento, geralmente branca. Se nada for feito, em pouco tempo provocando a quebra violenta do bloco e a projeção de partes em várias direções.

\section{METODOLOGIA}

\section{III.1 ANÁLISE DO POTENCIAL DE FALHA DOS MOTORES À DIESEL}

A prevenção de danos e falhas potenciais em equipamentos está associada a uma série de fatores, relacionadas à operação e à manutenção dos equipamentos, nas quais as principais falhas estão ligadas à falta lubrificação de motores, cujas partes podem provocar grande dano nas outras peças, folgas não previstas no projeto.

As causas das falhas no motor são geralmente determinadas relacionando-as a um ou a mais mecanismos de falha, causas mais significativas e recorrentes para a ocorrência desses problemas do disparo do motor são:

- Motores a diesel equipados com bombas injetoras mecânicas: mau funcionamento do regulador centrífugo (governador da bomba ou do blower nos motores 2 tempos), bicos injetores sem estanqueidade ou ajustes incorretos na dosagem do combustível [8].

- Motores com desgaste acentuado nos anéis dos pistões, provocam alimentação descontrolada do motor por óleo lubrificante, oriundo da ventilação do cárter ou do turbocompressor, tendem a pressurizar o cárter. Isso faz com que uma certa quantidade de lubrificante invada a admissão do motor através da ventilação do cárter. Se essa quantidade for excessiva o motor pode entrar em sobrerrotação(ultrapasse limite de giro do motor), inicia-se um ciclo vicioso: quanto mais a rotação do motor aumenta, maior é a pressão no interior do cárter, mais lubrificante é expulso do mesmo e entra na admissão, alimentando ainda mais o motor [8].

- Motores com turbocompressor, folga no mancal do compressor, o lubrificante sob pressão, que deveria permanecer nos mancais do eixo, adentra a admissão alimentando descontroladamente o motor [8].

Em todas essas situações, de nada adianta cortar a alimentação de óleo diesel (deligar motor, acionar start/stop ou tirar Bateria), pois o motor não está sendo mais alimentado pelo mesmo, não há qualquer tipo de controle na quantidade de ar que adentra no motor e as câmaras de combustão estão quentes o bastante para inflamar o óleo lubrificante admitido.

\section{III.2 SISTEMA DE PROTEÇAO CONTRA POTENCIAL DE FALHA DO MOTOR A DIESEL}

Muitas são as causas do disparo de um motor diesel sendo motor de ignição espontânea - MIE, os motores diesel não possuem controle da entrada de ar na admissão (borboleta). É uma característica dos motores a diesel, à alta taxa de compressão e no final do tempo da compressão, qualquer substância que se inflame a mais de $400^{\circ} \mathrm{C}$ pode funcionar como combustível. Apesar de óleo lubrificante não ser um combustível, mas se comportar como combustível 
Para evitar danos mais grave ao motor a diesel. Elaboramos um sistema de proteção contra potencial de falha dos motores a diesel (disparo do motor a diesel), um dispositivo parecido ao corpo de borboleta (Figura 3), o dispositivo funciona como válvula de bloqueio impedindo luxo de ar para admissão.
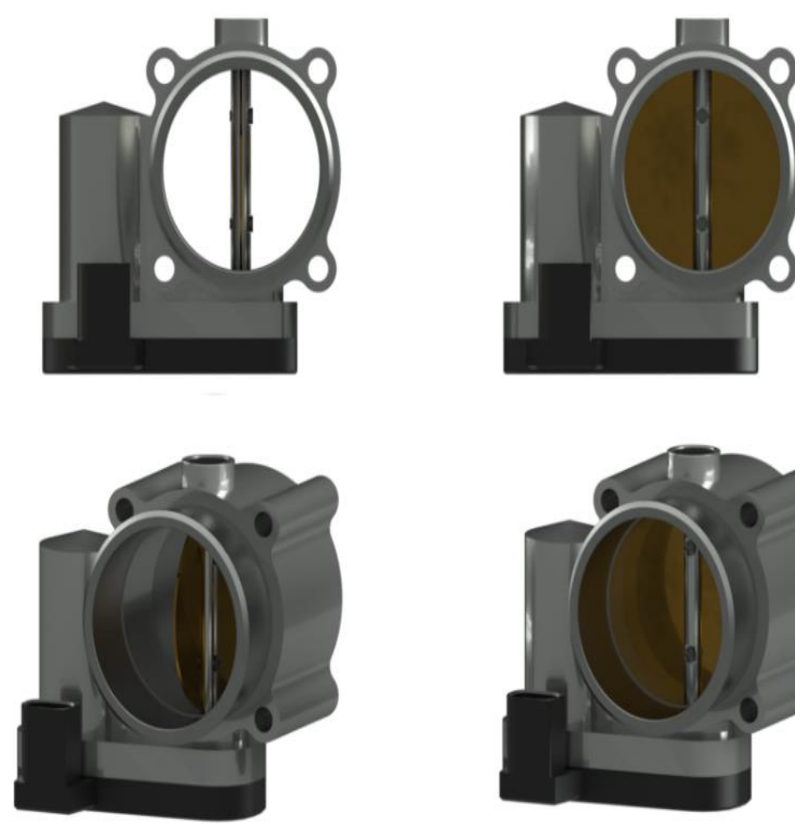

Figura 3. válvula de bloqueio.

Fonte: Autores, (2019).

Funcionamento do sistema de proteção contra potencial de falha do motor a diesel (disparo do motor). Dá-se através de um modulo de controle que monitora funcionamento do motor, através do sensor de rotação (RPM) mais adição de corpo de borboleta (válvula de bloqueio). Dados os parâmetros de funcionamento do motor ao detectar rotações além do limite de giro do motor, modulo de controle aciona o corpo de borboleta (válvula de bloqueio) da posição normalmente aberto N.A para posição Normalmente Fechado N.F ao acionar da posição N.A para N.F é feito corte injeção de combustível simultaneamente.

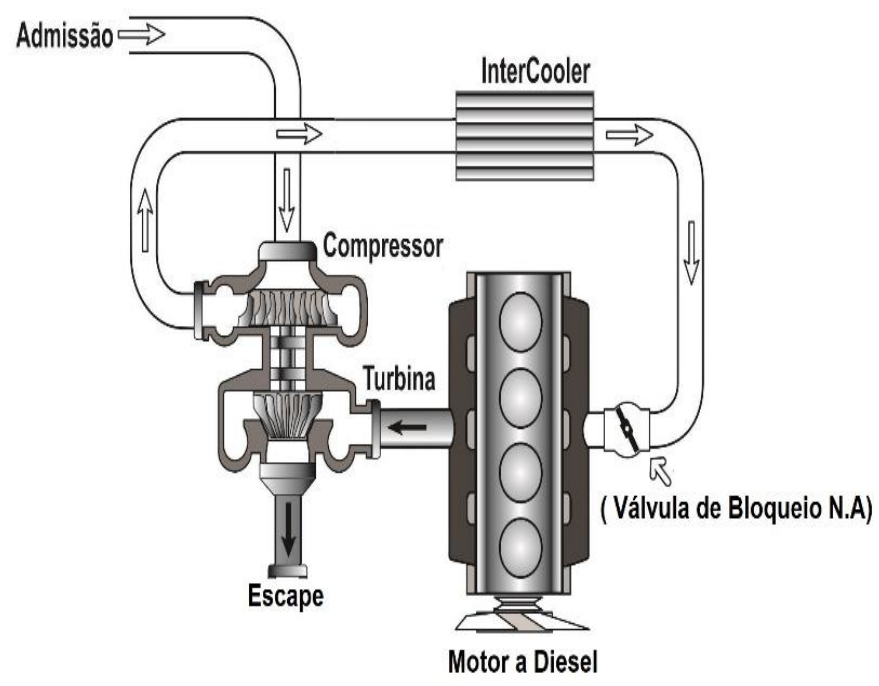

Figura 4: Motor à Diesel com válvula de bloqueio. Fonte: [7].
III.3 FUNCIONAMENTO DO SISTEMA DE PROTEÇÃO CONTRA POTENCIAL DE FALHA DO MOTOR A DIESEL

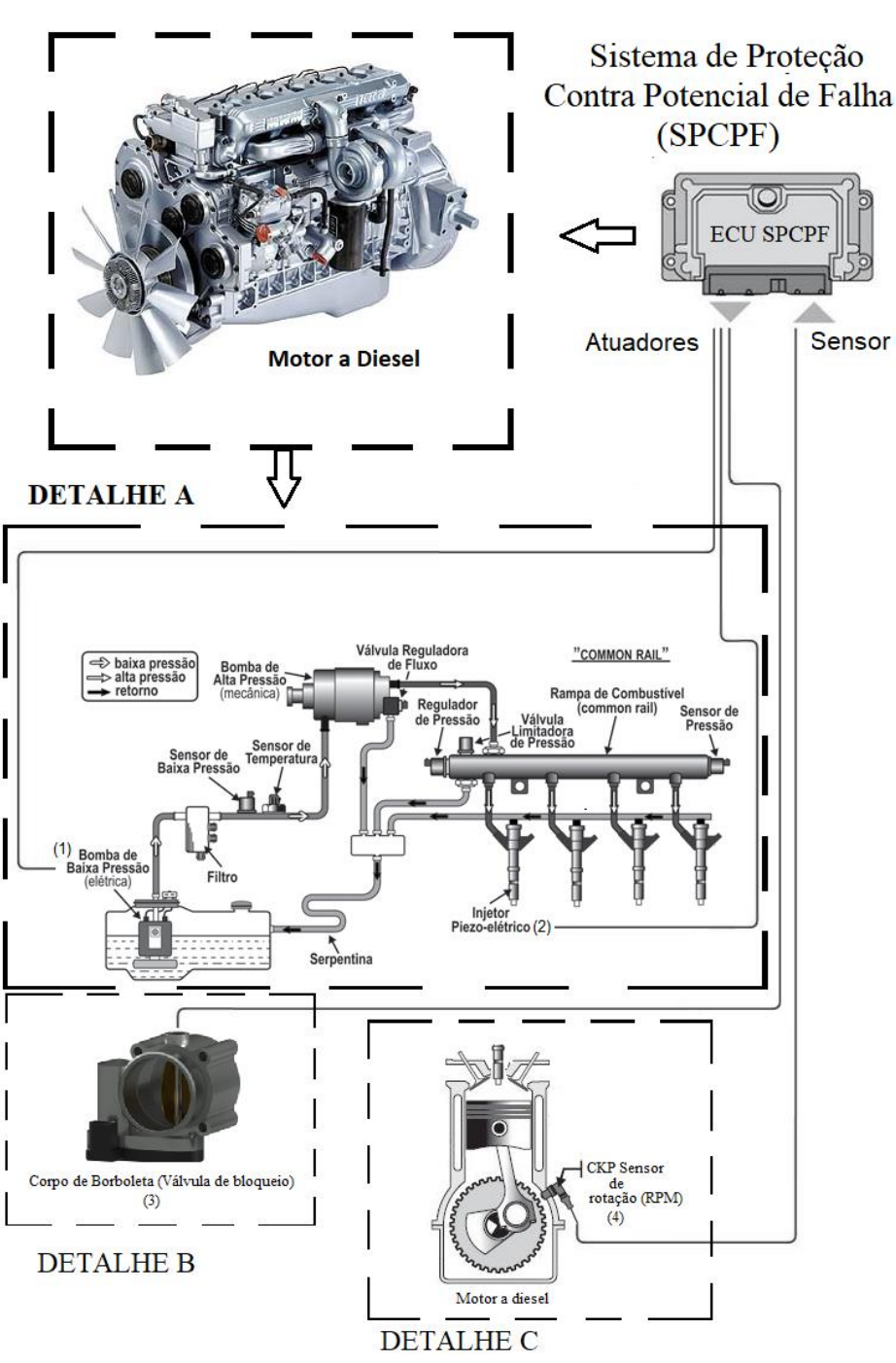

Figura 5: Diagrama de funcionamento.

Fonte: Autores, (2019).

\section{III.4 SISTEMAS DE ALIMENTAÇÃO DE COMBUSTÍVEL- DETALHE A}

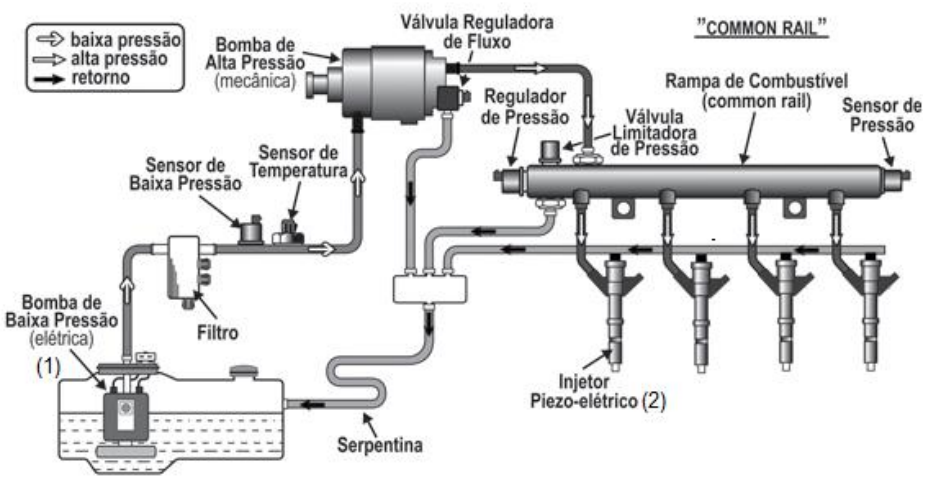

Figura 6: Monitor do Sistema de Combustível do Ciclo Diesel. Fonte: [6].

Os itens: (1) Bomba de Baixa Pressão (Elétrica) e (2) Injetor Piezo-Elétrico, do sistema de alimentação são itens fundamental para integração do sistema de proteção contra potencial de falha, onde (1) Bomba de baixa pressão (elétrica), será desligada. Assim cortando combustível. Tendo em vista que (2) 
Injetor Piezo-Elétrico. Pode ocorrer falha de estanqueidade do bico injetor. O mesmo será desligado.

\section{III.5 CORPO DE BORBOLETA (VÁLVULA DE BLOQUEIO) - DETALHE B}

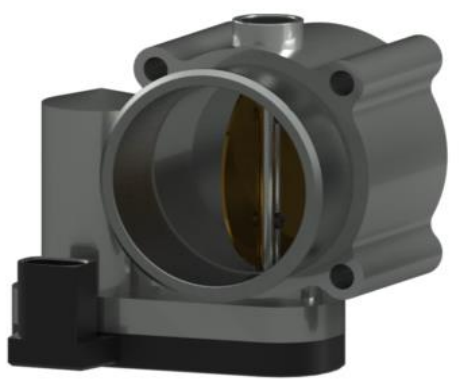

Figura 7: Válvula de bloqueio.

Fonte: Autores, (2019).

Itens: (3) corpo de borboleta (válvula de bloqueio). É implementado junto com sistema de proteção contra potencial de falha do motor a diesel. É dispositivo fundamental para sistema de proteção, tem a função de obstruir fluxo de ar no coletor de admissão, sendo válvula de bloqueio que atua somente em duas posições. Posição 1: Corpo de Borboleta totalmente aberto normalmente aberto N.A - ciclo normal de funcionamento do motor. E na posição 2: Corpo de Borboleta totalmente fechado, sendo válvula de bloqueio normalmente fechado N.F. Na posição dois sistemas de proteção foi ativado.

\section{III.6 SENSOR DE POSIÇÃO DO VIRABREQUIM (CRANKSHAFT POSITION SENSOR-KCP)-DETALHE C}

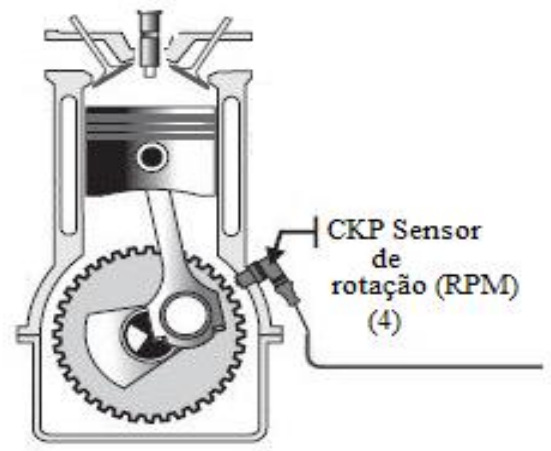

Motor a diesel

Figura 8: Sensor de Rotação. Fonte: [9].

Itens: (4) Sensor de Posição do Virabrequim ou Sensor de Rotação (CKP). Tem como objetivo fornecer A ECU SPCPF (Electronic Control Unit - Sistema de Proteção Contra Potencial de Falha). Rotação por minutos- RPM.

\section{III.7 SISTEMA DE PROTEÇÃO PARÂMETROS DE FUNCIONAMENTO (MÓDULO DE CONTROLE)}

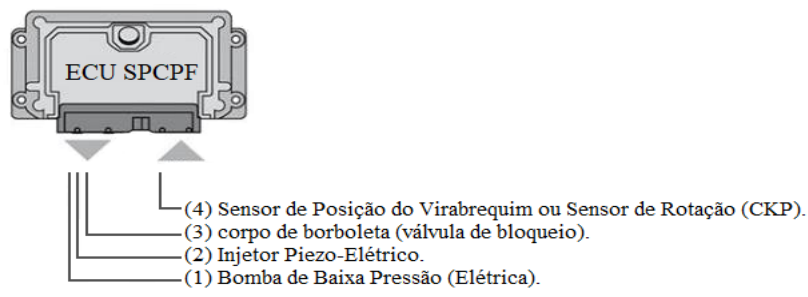

Figura 9: Electronic Control Unit - Sistema de Proteção Contra Potencial de Falha.

Fonte: Autores, (2019).
A ECU SPCPF (Electronic Control Unit - Sistema de Proteção Contra Potencial de Falha) está programada para receber os sinais lidos pelos sensores do motor, analisar estas informações e decidir quais os parâmetros de funcionamento e determinada situação à qual o motor está sendo submetido.

- (4) Sensor de Posição do Virabrequim ou Sensor de Rotação (CKP): informar rotação do motor, existe um sistema automático na injeção que não deixa o ponteiro entrar na faixa vermelha do conta-giros (Tacômetro), o combustível é cortado e o motor não vai além do giro máximo permitido.

- (3) Corpo de Borboleta (Válvula de bloqueio): Tem a função de obstruir fluxo de ar para admissão, atuando como válvula de bloqueio, que atua somente em duas posições: Posição 1 - Corpo de Borboleta totalmente aberto, sendo válvula de bloqueio normalmente aberto N.A. Posição 2 - Corpo de Borboleta totalmente fechado, sendo válvula de bloqueio normalmente fechado N.F.

(3.1) Corpo de Borboleta: Válvula de bloqueio travado na posição normalmente aberto N.A.

\section{III.8 ATIVAÇÃO DO SISTEMA DE PROTEÇÃO (MÓDULO DE CONTROLE)}

A ECU SPCPF (Electronic Control Unit - Sistema de Proteção Contra Potencial de Falha). analisa as informações do sensor de rotação e monitora os parâmetros de funcionamento determinado, à qual o motor está sendo submetido. Ao detectar falha, disparo do motor, o módulo de controle aciona, nas seguintes ordens:

- Acionamento da luz de anomalia no painel e alerta sonoro.

- Aciona o Corpo de Borboleta (Válvula de Bloqueio) da posição normalmente aberto N.A para posição Normalmente Fechado N.F, ao acionar da posição N.A para N.F é feito corte injeção de combustível simultaneamente

- Corte no Sistema de Alimentação de Combustível: (1) Bomba de Baixa Pressão (Elétrica), (2) Injetor Piezo-Elétrico, impossibilitando nova partida depois da ativação do sistema. Essa impossibilidade de ativação se dá por questão de segurança, evitando procrastinação nas manutenções necessárias ao motor.

- Acionamento manual: acionado através de um botão específico e lacrado. (redundância do sistema)

\section{RESULTADOS E DISCUSSÕES}

Embora a larga utilização dos Motores de ignição espontânea - (MIE), sua confiabilidade vem se comprovando há séculos, desde sua criação em 1913, principalmente com avanço na engenharia de motores de combustão interna (MCI). Entretendo falta de manutenção ou manutenção imprópria eleva aumento do desgaste natural, com aumento de folgas não prevista no projeto, motor à diesel ainda tem sua confiabilidade comprovado.

Atualmente o potencial de falha crítica do motor diesel, o disparo do motor diesel, vem ocorrendo nos motores Turbo Diesel. O turbocompressor se faz necessário pelo aumento de eficiência energética, com aumento da potência em torno de $35 \%$ e reduz o consumo específico de combustível em torno de 5\% [5]. A falha gerada no turbocompressor se dá basicamente pela falta de manutenção ou lubrificante não recomendado. falta momentânea ou lubrificante impróprio que causa a ruptura do filme lubrificante. Assim provocando danos e folgas nos mancais do turbocompressor, devido excesso de folga no mancal do compressor o lubrificante sob pressão, que deveria permanecer nos 
mancais do eixo, adentra a admissão alimentando descontroladamente o motor.

Devido arrobusteis dos motores à Diesel, ocorrem de muitas vezes negligenciando manutenção preventiva, principalmente um componente crítico como turbocompressor. Seja por falta conhecimento técnico ou falta de mão de obra qualificada.

O sistema de proteção contra potencial de falha do motor à diesel (disparo do motor), é extremamente necessário, preservando motor de eventuais danos. Sabendo que fenômeno provocado pelo disparo do motor dá-se através de componente auxiliar ao motor, turbocompressor, pelo mau funcionamento. Embora o motor á diesel goza de perfeita saúde mecânica.

\section{CONCLUSÃO}

Este artigo apresentou uma hipótese para solução de um problema comum encontrado nos motores à diesel, baseando-se nos conceitos gerais de operações e parâmetros de funcionamento do motor de ignição por compressão (MIE), que fundamentaram o desenvolvimento do sistema de proteção contra potencial falha dos motores a diesel, assim como a pesquisa que possibilitou as comprovações das hipóteses, antes levantadas, o projeto ainda necessita ser testado por meio de um protótipo para que sejam simuladas as diversas condições reais a que o motor à diesel está exposto e que pode gerar a falha em questão. A modelagem do projeto foi comprovada pelo referencial teórico, uma vez que a impossibilidade de admissão de ar interrompe o fluxo do ar para dentro do motor. Sendo assim, o objetivo alcançado resultou da determinação dos esforços, a criação do projeto inicial do mecanismo, utilizando modelo teórico e estabelecendo uma primeira visão do esboço do protótipo. Uma vez determinado a forma e os materiais de construções do protótipo e definido parâmetros de funcionamento do sistema de proteção contra potencial de falha do motor à diesel, é possível que seja fabricado e testado em um ambiente controlado.

\section{REFERÊNCIAS}

[1] Fleming, Paulo V. França Sandro R.R.O.; Considerações Sobre a implementação Conjunta de TPM e MCC na Indústria de Processos; Abraman; 1997

[2] Brunetti, Franco - "Motores de combustão interna". Vol.2 Editora Blucher, 2012. ISBN: 9788521207092

[3]. Martins, Jorge - "Motores de combustão interna". 2. ${ }^{\text {a }}$ ed. Porto : Publindústria, 2006. ISBN 972-8953-82-X.

[4] Bezerra. Daniel Portela. Estudo sobre os processos físicos envolvidos nos motores que utilizam como combustíveis óleos (Ciclo Diesel). Disponível em: <https://www.ucb.br/sites/100/118/TCC/2\%C2\%BA2007/TCCDa nielPortelaBezerra.pdf>. Acesso em 4 de Março 2018.

[5] Varella \& Santos, 2010 - Noções Básicas de Motores Diesel. Disponível em: <http://www.ufrrj.br/institutos/it/deng/varella/Downloads/IT154_ motores_e_tratores/Literatura/No\%E7\%F5es\%20B\%E1sicas\%20 de\%20Motores\%20Diesel.pdf>. Acesso em 4 de Março 2018,

[6] Humberto Manavella, Monitor do Sistema de Combustível do Ciclo Diesel determina a mistura do ar e do combustível. Disponível
$<$ https://www.oficinabrasil.com.br/noticia/tecnicas/monitor-dosistema-de-combustivel-do-ciclo-diesel-determina-a-mistura-doar-e-do-combustivel>. Acesso em 4 de Março 2018.

[7] Humberto Manavella, Monitor do Catalisador com sistema Adsorvente de NOx - LNT Lean NOx Traps - 2018. Disponível em: $<$ https://www.oficinabrasil.com.br/noticia/tecnicas/monitordo-catalisador-com-sistema-adsorvente-de-nox-lnt-lean-noxtraps>. Acesso em 4 de Março 2018,

[8] Fernando Landulfo, O Motor Diesel Disparou! E agora?, pg. 46 - 2018. Disponível em: <https://www.omecanico.com.br/wpcontent/uploads/2018/04/Mecanico_ed288_SITE.compressed.pdf >. Acesso em 9 de Setembro 2018.

[9] MTE-Thomson, Introdução aos sistemas de Injeção E Ignição Eletrônica. Disponível em: <https://cursosonline.mtethomson.com.br/unit/aula-01-introducao-aos-sistemas-de-injecaoe-ignicao-eletronica/> . Acesso em: 10 novembro. 2018. 